\title{
Preliminary Review of the Effects of Electronic Medical Administration Records (eMAR) and Electronic Doctor Order Entry (CPOE) on Patient Safety Culture in the Era of Universal Health Services
}

(Tinjauan Awal Pengaruh Catatan Administrasi Pengobatan Secara Elektronik [eMAR] dan Entry Perintah Dokter Secara Elektornik [CPOE] pada Budaya Keselamatan Pasien di era Pelayanan Kesehatan Semesta)

\author{
Rahmat Santoso'; Stefanus Nova² \\ email: santozr64@gmail.com
}

Bandung College of Pharmacy [STFB] $]^{1}$ and PP IAI Community Pharmacy Seminate Association ${ }^{1}$ GWS Care [Your Personal Pharmacy \& Health Assistant] ${ }^{2}$

\begin{abstract}
In the era of universal health service [UHC], medicine was always used as part of curative, preventive, and promotive. Following pharmaceutical service standards in hospitals, health centers, and pharmacies, that medicines must be managed properly, including in their use. Medication errors are a leading cause of death in many parts of the world. The factors causing the increase in medication errors related to individuals, such as heavy workload on health care facilities and pharmaceutical service facilities, are often experienced by medical staff (General Practitioners and Specialists) and pharmaceutical personnel (Pharmacists and Pharmaceutical Technical Personnel / TTK), or organizational-related factors, such as inadequate facilities and infrastructure to document medication administration records and the entry of physician orders electronically. The study was conducted cross-sectionally retrospectively, by sharing the results of an initial literature review on the impact of electronic medication administration records (eMAR) and doctor's order entry (CPOE) on patient safety. Using PubMed and Google Scholar, we search for the following terms: "eMAR", "CPOE", "medication error", and "patient safety". Our initial findings reveal that eMAR and CPOE can have an impact on the pharmaceutical workflow, and reduce medication errors, thereby increasing patient safety. Based on the initial review, eMAR and CPOE influence the insight of pharmaceutical personnel, pharmaceutical workflows and impact on patient safety. On the other hand, there is a regulatory direction which is still in the form of a Regulation of the Minister of Health Regulation on Providers of Electronic Pharmaceutical Facilities (PSEF), but it is unfortunate that "eMAR" and "CPOE" have not become clauses governed by the government. Our plan for future research is to conduct a systematic review study to further study the impact of eMAR and CPOE on patient safety.
\end{abstract}

Keywords: Electronic Medical Administration Notes (eMAR), CPOE, PSEF, Medication Errors; Patient safety 


\section{PENDAHULUAN}

Dari sekian banyak referensi ilmiah, yang dianggap sebagai rujukan utama mengenai pengertian Rekam Medis Elektronik adalah laporan dari National Alliance for Health Information Technology (NAHIT) pada tahun 2008 kepada Office of the National Coordinator for Health Information Technology. Dalam laporan tersebut, NAHIT membedakan rekam medis elektronik (RME), rekam kesehatan elektronik (RKE) dan rekam kesehatan personal (RKP)

Perbedaan RME, RKE dan RKP

Tabel 1. Pengertian RME, RKE dan RKP

\begin{tabular}{|c|c|c|}
\hline $\begin{array}{c}\text { Rekam medis elektronik } \\
\text { (RME) }\end{array}$ & $\begin{array}{l}\text { Rekam kesehatan elektronik } \\
\text { (RKE) }\end{array}$ & $\begin{array}{c}\text { Rekam kesehatan personal } \\
\text { (RKP) }\end{array}$ \\
\hline $\begin{array}{l}\text { Rekaman/catatan } \\
\text { elektronik mengenai } \\
\text { informasi kesehatan } \\
\text { individu yang yang } \\
\text { dibuat, dikumpulkan, } \\
\text { dikelola, digunakan dan } \\
\text { dirujuk oleh dokter atau } \\
\text { tenaga kesehatan yang } \\
\text { berwenang di satu } \\
\text { organisasi pelayanan } \\
\text { kesehatan }\end{array}$ & $\begin{array}{l}\text { Rekaman/catatan elektronik } \\
\text { mengenai } \\
\text { informasi kesehatan individu } \\
\text { yang mengikuti standar } \\
\text { interoperabilitas nasional dan } \\
\text { dibuat, dikumpulkan, dikelola, } \\
\text { digunakan dan dirujuk oleh } \\
\text { dokter atau tenaga kesehatan } \\
\text { yang berwenang pada lebih } \\
\text { dari satu organisasi } \\
\text { pelayanan kesehatan }\end{array}$ & $\begin{array}{l}\text { Rekaman/catatan elektronik } \\
\text { mengenai } \\
\text { informasi kesehatan yang } \\
\text { mengikuti standar } \\
\text { interoperabilitas nasional } \\
\text { dan dapat ditarik dari } \\
\text { berbagai sumber namun } \\
\text { dikelola, dibagi } \\
\text { serta dikendalikan oleh } \\
\text { individu (pasien). }\end{array}$ \\
\hline
\end{tabular}

\section{Fungsi RME}

Dalam suatu laporan yang komprehensif mengenai RKE, Institute of Medicine menjelaskan 8 fungsi rekam kesehatan elektronik, yang terbagi menjadi 4 fungsi utama dan 4 fungsi lain (lihat Tabel 2). Suatu aplikasi dapat disebut sebagai RME jika minimal memenuhi 4 kriteria utama dan dijalankan dalam satu lingkup organisasi.

Tabel 2. Fungsi RKE

\begin{tabular}{|l||l||}
\hline \multicolumn{1}{|c|}{ Fungsi utama } & \multicolumn{1}{|c|}{ Fungsi lainnya } \\
\hline \hline $\begin{array}{l}\text { Data dan informasi kesehatan: diagnosis } \\
\text { medik dan keperawatan, daftar } \\
\text { pengobatan, alergi, demografi, informasi } \\
\text { klinis yang bersifat naratif atau terstruktur, } \\
\text { hasil laboratorium }\end{array}$ & $\begin{array}{l}\text { Komunikasi dan konektivitas secara } \\
\text { elektronik:memungkinkan siapa saja yang } \\
\text { terlibat dalam perawatan pasien saling } \\
\text { berkomunikasi satu sama lain serta } \\
\text { komunikasiantara tenaga kesehatan dengan } \\
\text { pasien melalui email, Web, perangkat } \\
\text { perpesanan dan telemedicine }\end{array}$ \\
\hline
\end{tabular}




\begin{tabular}{|l||lr||}
\hline $\begin{array}{l}\text { Manajemen hasil (result management): } \\
\text { mengelola seluruh hasil pemeriksaan } \\
\text { (misal laboratorium dan radiologi) secara } \\
\text { elektronik }\end{array}$ & $\begin{array}{l}\text { Dukungan bagi pasien: materi promosi } \\
\text { kesehatan, penyuluhan sampai dengan } \\
\text { pemantauan di rumah atau telehealth }\end{array}$ \\
\hline \hline $\begin{array}{l}\text { Pemasukkan perintah (order entry): } \\
\text { penerapan pemasukan perintah oleh } \\
\text { petugas secara elektronik (computerized } \\
\text { provider order entry) khususnya dalam } \\
\text { memasukkan pengobatan }\end{array}$ & $\begin{array}{l}\text { Administratif: memudahkan proses } \\
\text { penjadwalan, otorisasi, verifikasi asuransi, } \\
\text { program manajemen penyakit kronik, sampai } \\
\text { dengan uji klinik }\end{array}$ \\
\hline \hline $\begin{array}{l}\text { Pendukung keputusan (decision } \\
\text { support): fasilitas pendukung keputusan } \\
\text { berbasis komputer, misalnya pengingat, } \\
\text { alert, maupun diagnosis berbantuan } \\
\text { komputer }\end{array}$ & $\begin{array}{l}\text { Pelaporan } \\
\text { masyarakat: mengikuti standar terminologi } \\
\text { dan format data untuk pelaporan kesakitan } \\
\text { dan surveilans }\end{array}$ \\
\hline \hline
\end{tabular}

Menggunakan pengertian di atas, apakah PCare dapat disebut sebagai RME, RKE, RKP atau bukan ketiga-tiganya?

Bagaimana pula dengan berbagai sistem aplikasi yang sudah digunakan di beragam fasilitas kesehatan baik puskesmas maupun rumah sakit, seperti Simpus Jojok, SIKDA Generik, IHIS, Sisfomas, epuskesmas, EHR di RSCM, EHR di RS Akademik UGM, aplikasi di Gadjah Mada Medical Center, aplikasi di RS Eka Hospital, aplikasi InterSystemTrakCare di RS Pondok Indah, dan masih banyak lagi?

Bagaimana dengan eMAR dan CPOE, pada fasilitas pelayanan kefarmasian (Fasyanfar) yang belum pernah ada dalam praktek kefarmasian, maka kami mengangkat judul penelitian ini, agar ada pemangku kepentingan yang peduli, dan sebagai bentuk tanggung jawab moral obligasi sebagai tanaga kefarmasian.

\section{PERUMUSAN MASALAH}

Pelayanan kefarmasian merupakan bagian dari pelayanan kesehatan yang sangat dibutuhkan pada era pelayanan kesehatan semesta. Meningkatkan mutu pelayanan kefarmasian dapat dilakukan dengan memanfaatkan perkembangan teknologi kesehatan berbasis elektronik/digital/"paperless" atau dikenal sebagai “big data”, merupakan keniscayaan.

Teknologi di dunia kesehatan untuk membantu pekerjaan tenaga kesehatan, salah satunya menggunakan Sistem Electronic Medication Administration Record (EMAR) atau catatan elektronik penatalaksanaan pemberian obat yang terintegrasi dengan jejaring fasilitas pelayanan kefarmasian dan Sistem Entry Perintah Dokter (CPOE) atau aplikasi perintah penggunaan obat berbasis komputer. Kedua teknologi tersebut bermanfaat untuk meminimalkan kesalahan dalam pemberian/penggunaan obat (medication error) pada pasien, serta sejalan dengan tercapainya pasien safety. 
Untuk mewujudkan implementasi eMAR dan CPOE, dibutuhkan regulasi yang adequat, maka dilakukan kajian sejauh mana regulasi yang ada, berupa UU, PP, Perpres, Inpres, Permenkes, Perka BPOM, mampu menjawab tantangan dalam pendokumentasian secara elektronik.

\section{METODE PENELITIAN}

Penelitian ini dilakukan secara retrospektif cross sectional, dengan berbagi hasil tinjauan literatur awal tentang dampak catatan administrasi pengobatan elektronik (eMAR) dan entri perintah dokter (CPOE) pada keselamatan pasien. Menggunakan PubMed dan Google Cendekia, kami mencari istilah berikut: "eMAR", "CPOE", "kesalahan pengobatan", dan "keselamatan pasien". Kemudian dikaitkan dengan kesiapan regulasi kefarmasian yang berhubungan dengan "eMAR dan CPOE" di Indonesia.

\section{PEMBAHASAN}

Beberapa rumah sakit di Indonesia masih belum menggunakan teknologi berbasis komputer dalam penulisan resep obat, atau dapat dikatakan menggunakan penulisan resep obat secara tertulis. Padahal, pendokumentasian secara tertulis mempunyai banyak ancaman terjadinya medication error, seperti sering hilang/terselipnya resep obat, tulisan yang tidak jelas, salah dalam penulisan sehingga pada akhirnya perawat dan apoteker yang terkena dampak dan berujung pada medication error. Begitu juga dalam dokumentasi catatan pengobatan pasien (eMAR) merupakan salah satu cara untuk mencegah terjadinya medication error.

Pada era UHC, puskesmas sebagai "gate keeper" dengan jumlah pasien yang sangat banyak, masih banyak yang belum menggunakan teknologi berbasis computer, dengan berbagai kondisi keterbatasan sumber daya, sehingga medication error sulit untuk dihindari, apalagi dengan jumlah puskesmas > 6.500. eMAR dan CPOE di puskesmas sudah selayaknya dapat diterapkan secara bertahap di puskesmas yang telah bekerja sama dengan BPJS.

Keberadaan apotek jejaring BPJS yang melayani program PRB dan Prolanis, sudah selayaknya menerapkan eMAR dan CPOE secara bertahap, hal ini untuk mencegah terjadinya medication error, serta terwujudnya pasien safety. Apotek jejaring yang melayani PRB dan Prolanis telah mencapai > 2.500.

Ketidak patuhan dalam penggunaan obat oleh pasien juga termasuk dalam medication error. Ketika pasien masih berada di rumah sakit, tentu tugas perawat dan apoteker untuk mengingatkan mengkonsumsi obat. Namun, ketika pasien diperbolehkan pulang, sering mendapat keluhan bahwa obat tidak dikonsumsi secara tepat di karenakan tidak ada keluarga yang mengingatkan, pasien lupa atau pasien malas mengonsumsi obat.

Berdasarkan penelusuran mesin pencari data, PubMed, dan Google Cendekia, EMAR dan CPOE telah banyak dimanfaatkan oleh negara maju, seperti di Amerika serikat. Beberapa contoh hasil penelusuran mesin pencari data, diperoleh tema dan tujuan penelitian, hasil penelitian, dan kesimpulan sebagai berikut:

1. Tema: Kualitas Administrasi Medis Dan Teknologi Informasi Kesehatan, Studi Nasional Rumah Sakit di Amerika Serikat

Objektif: Untuk menentukan apakah penggunaan entri perintah dokter yang terkomputerisasi atau computerized physician order entry (CPOE) dan catatan administrasi pengobatan berbasis elektronik atau electronic medication administration 
records (eMAR) dikaitkan dengan kualitas yang lebih baik dari administrasi obat di rumah sakit perawatan sedang hingga besar.

Hasil : Dibandingkan dengan rumah sakit yang tidak mengadopsi/memakai eMAR dan CPOE, hasilnya menunjukkan bahwa tingkat kepatuhan pasien pada rumah sakit yang hanya menggunakan eMAR lebih rendah yakni sebesar $14-29 \%$ pasien dibandingkan dengan rumah sakit yang menggunakan kedua teknologi ( $\mathrm{eMAR} \&$ CPOE) yakni sebesar 13-38\% ,presentasi ini dikonvert ke dalam satuan marjinal dimana terdapat peningkatan $0,4-2,0$ persen. Lebih lanjut, setiap 2 tahun penggunaan teknologi, peningkatan presentasi kepatuhan pasien dperkiran meningkat sebesar 6-15\% yang mana lebih tinggi pada rumah sakit yang hanya menggunakan eMAR dan Rumah sakit yang menggunakan kedua teknologi tersebut.

Kesimpulan : Implementasi dan durasi penggunaan teknologi informasi kesehatan dikaitkan dengan peningkatan kepatuhan terhadap pedoman pengobatan di rumah sakit AS. Manfaatnya adalah bukti untuk mengadopsi sistem eMAR sendiri dan dalam kombinasi dengan CPOE.

2. Tema: Dampak Dari Catatan Administrasi Medikasi Elektronik Atau Electronic Medication Administration Records (Emar) Dan Entri Pesanan Dokter Terkomputerisasi Atau Computerized Physician Order Entry (Cpoe) Pada Perawat Pembantu Dan Staf Petugas Unit.

Objektif: Tujuan dari penelitian ini adalah untuk menggambarkan/menjelaskan dampak dari pengenalan teknologi informasi kesehatan (HIT) pada pemanfaatannya \& pembiayaan atau penggajian perawat pembantu, staf unit obat-obatan dan staf unitoperasi dalam sistem kesehatan daerah yang besar.

Hasil : Sasaran kebijakan jangka panjang dari implementasi Digital Health yang dilaporkan mencakup pengurangan biaya pada sistem tenaga kerja, yang dicapai melalui perbaikan kualitas tenaga kerja. Dengan menggunakan retrospective cohort model, kami menganalisis jam kerja dan biaya/gaji per hari para staf yang bervariasi dalam penerapan Digital Health dari waktu ke waktu di 2 rumah sakit yang berbeda dalam mengaplikasikan sistem kesehatan. Implementasi catatan administrasi pengobatan elektronik tidak terkait dengan perubahan signifikan dalam staf atau biaya tenaga kerja. Baik jam kerja dan biaya para perawat pembantu dan staff Unit adminstrasi berkurang secara signifikan setelah melakukan implementasi system Catatan Pengobatan Secara Elektronik (eMAR) dan Entri Pesanan Dokter Terkomputerisasi atau computerized physician order entry (CPOE). Secara bersamaan, rumah sakit yang tidak menerapkan Digital Health mengalami penambahan yang signifikan dalam jam kerja dan biaya.

Kesimpulan : Implementasi teknologi informasi kesehatan sangatlah efektif dalam pengaturan/penetuan jam kerja dan biaya/gaji para tenaga para medis yang tidak terdaftar/tanpa kontrak/perawat pembantu.

Untuk menentukan apakah penggunaan entri perintah dokter yang terkomputerisasi atau computerized physician order entry (CPOE) dan catatan administrasi pengobatan berbasis elektronik atau electronic medication administration records (eMAR) dikaitkan dengan kualitas yang lebih baik dari administrasi obat di rumah sakit perawatan sedang hingga besar. Namun, pemanfaatan eMAR dan CPOE belum berjalan di Indonesia. Pemanfaatan eMAR dan CPOE bisa diterapkan di Indonesia dengan melaksanakan manajemen yang baik. 
Cara penggunaan eMAR dimulai dengan melakukan login user name dan password, mengisi data identitas pasien, mengunggah foto, mengisi bentuk obat yang diberikan, waktu pemberian obat, dosis obat, mengisi jenis alergi, dll. Apoteker dan Perawat mendokumentasikan menggunakan eMAR setelah menyiapkan obat dan akan mendokumentasikan ulang setelah memberikan pengobatan. Manfaat eMAR bagi apoteker dan perawat untuk memperbaiki kepatuhan terhadap pendokumentasian pengobatan, mengurangi kesalahan dalam pendokumentasian, mengurangi kemungkinan lupa untuk memberikan obat,

Sedangkan SMAA menggunakan Fitur OS yang dirancang untuk membantu pasien, perawat, dan apoteker dalam memperbaiki perilaku minum obat. Terdapat 3 perangkat yang digunakan Apple, Android, Blackberry. Aplikasi yang digunakan seperti MyMeds, MyMedSchedule dan RxmindMe. SMAA bermanfaat untuk memantau ketaatan pasien, seperti waktu minum obat, dosis pil atau obat, pemantauan biologis dan pemantauan elektronik menggunakan smarthphone. SMAA merupakan aplikasi yang tidak mahal, terukur, dapat diakses oleh siapa saja yang memilki smarthphone dan tidak memerlukan perangkat khusus.

Payung hukum berupa standar pelayanan kefarmasian di rumah sakit (Permenkes 72 tahun 2016), apotek (Permenkes 73 tahun 2016), dan puskesmas (Permenkes 74 tahun 2016) menjadi acuan bagi tenaga kefarmasian dalam menjalankan tugasnya. Bahkan instrument akreditasi rumah sakit dan puskesmas dalam hal pengelolaan obat, menggunakan parameter standar pelayanan kefarmasian. Peraturan Badan POM No. 4 Tahun 2018 tentang pengawasan pengelolaan obat, bahan obat, narkotika, psikotropika dan prekursor farmasi di fasilitas pelayanan kefarmasian, khususnya dalam Teknis Tata Kelola Obat. Serta Perka BPOM No. 28 Tahun 2018 tentang pedoman pengelolaan obatobat tertentu yang sering disalahgunakan, utamanya dalam memasukkan Dextromethorphan sebagai obat-obat tertentu.

Sistim manajemen mutu yang berupa dokumentasi secara offline atau online, menjadi isu strategis pada era pelayanan kesehatan semesta (UHC), apalagi saat menjelang akreditasi rumah sakit dan puskesmas. Walaupun akreditasi apotek belum memiliki payung hokum, namun penerapan aspek system dokumentasi bagi apotek jejaring BPJS, merupakan hal yang mutlak saat kredensial oleh pemangku kepentingan.

Nomenklatur administrasi, pencatatan, pelaporan dalam regulasi tersebut di atas, menjadi perhatian utama bagi tenaga kefarmasian dalam menjalankan prakteknya. Bila administrasi, pencatatan, dan pelaporan dilakukan secara manual, tentunya akan mengalami berbagai kendala seperti : Pemanasan global karena penggunaan kertas yang sangat banyak, potensi kehilangan dokumen, penumpukan dokumen, waktu pencarian dokumen menjadi lama, dokumen real time sulit untuk dipenuhi, potensi kehilangan omset karena sulitnya mengambil keputusan bisnis, yang juga penting adalah potensi kesalahan pengobatan (mediaction error) menjadi sulit untuk dihindari.

Maka menjadi isu strategis dalam mewujudkan budaya keselamatan pasien pada era pelayanan kesehatan semesta, bahwa penggunaan digital health atau elektronik pencatatan pengobatan pasien (eMAR) dan CPOE, sudah saatnya diwujudkan. Maka dibutuhkan regulasi yang adequate, serta kepekaan pemangku kepentingan yang sudah mulai merespon positif, seperti implementasi Online single submission (OSS) atau perizinan berusaha terintegrasi secara elektronik. 


\begin{tabular}{|c|c|c|c|}
\hline $\begin{array}{c}\text { Rumah Sakit } \\
\text { (PMK 72/2016) }\end{array}$ & $\begin{array}{c}\text { Apotek } \\
\text { (PMK 73/2016) }\end{array}$ & $\begin{array}{c}\text { Puskesmas } \\
\text { (PMK 74/2016) }\end{array}$ & $\begin{array}{c}\text { PerBPOM } \\
4 / 2018 \\
\end{array}$ \\
\hline Pemilihan & - & - & - \\
\hline Perencanaan & Perencanaan & Perencanaan & - \\
\hline Pengadaan & Pengadaan & Permintaan & Pengadaan \\
\hline Penerimaan & Penerimaan & Penerimaan & Penerimaan \\
\hline Penyimpanan & Penyimpanan & Penyimpanan & Penyimpanan \\
\hline Pendistribusian & - & Pendistribusian & Penyerahan \\
\hline $\begin{array}{l}\text { Pemusnahan dan } \\
\text { Penarikan }\end{array}$ & $\begin{array}{l}\text { Pemusnahan dan } \\
\text { Penarikan }\end{array}$ & $\begin{array}{l}\text { Pemusnahan dan } \\
\text { Penarikan }\end{array}$ & $\begin{array}{l}\text { Pengembalian } \\
\text { Pemusnahan }\end{array}$ \\
\hline Pengendalian & Pengendalian & Pengendalian & - \\
\hline Administrasi & $\begin{array}{l}\text { Pencatatan dan } \\
\text { Pelaporan }\end{array}$ & Administrasi & Pelaporan \\
\hline - & - & Pemantauan dan evaluasi & - \\
\hline
\end{tabular}

\section{1) PEDOMAN TEKNIS PENGELOLAAN OBAT DAN BAHAN OBAT BADAN POM RI DI FASILITAS PELAYANAN KEFARMASIAN (Per BP0M No.4 Tahun 2018)}

CAKUPAN PENGELOLAAN

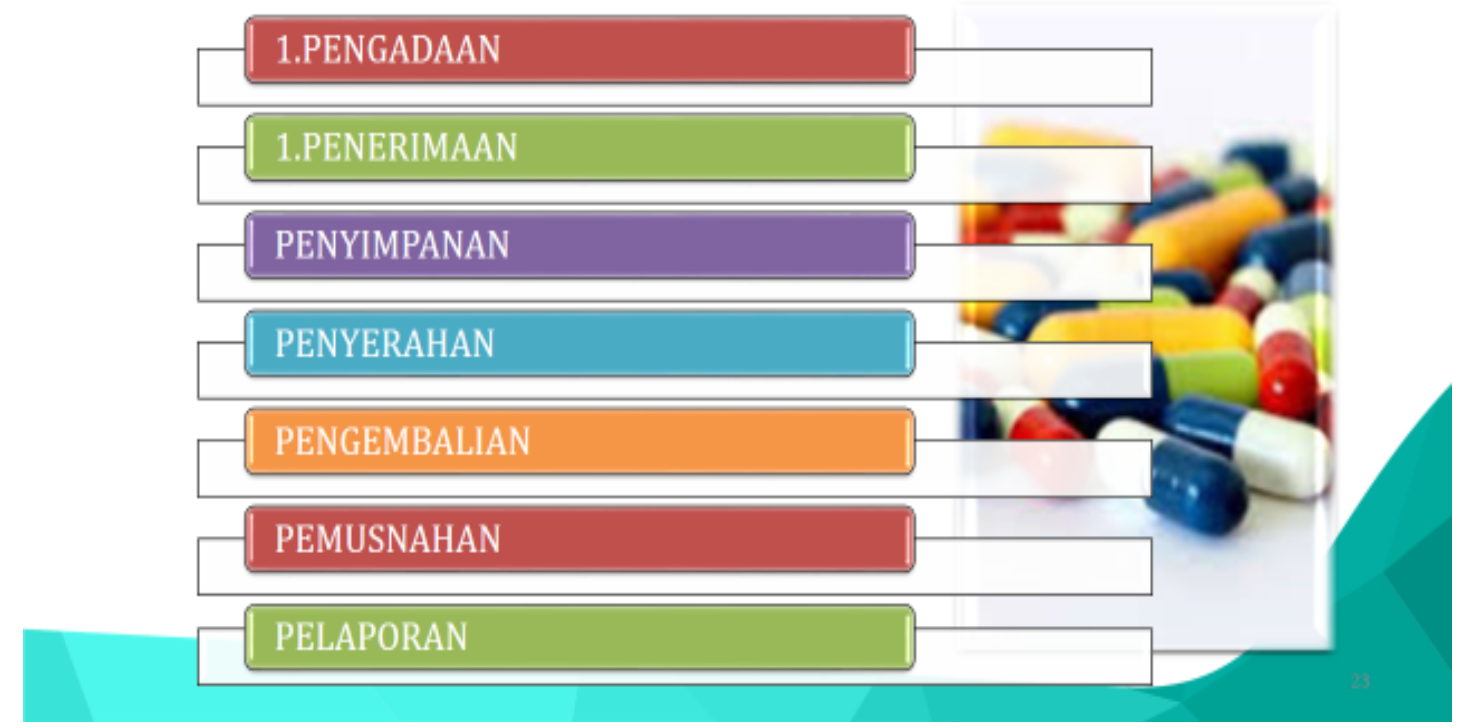

BPOM sedang melakukan upaya sistim berlapis dalam pengawasan obat, bahkan dengan hadirnya Deputi Penindakan serta Loka BBPOM di berbagai daerah, apalagi RUU Pengawasan Obat sudah masuk prolegnas, menjadi isu strategis bagi tenaga kesehatan termasuk tenaga kefarmasian, untuk mempersiapkan sistim dokumentasi mutu secara elektronik yang mampu telusur. Pada era pelayanan kesehatan semesta 


\section{Surat Pesanan}

BADAN POM RI

Harus Mencantumkan:

nama sarana sesuai izin (disertai nomor izin) dan alamat lengkap (termasuk nomor telepon/ faksimili bila ada) dan stempel sarana

nama fasilitas pemasok beserta alamat lengkap

- nama, bentuk dan kekuatan sediaan, jumlah (dalam bentuk angka dan huruf) dan isi kemasan (kemasan penyaluran terkecil atau tidak dalam bentuk eceran) dari Obat/Bahan Obat yang dipesan:

nomor urut surat pesanan, nama kota dan tanggal dengan penulisan yang jelas:

- harus bisa menjamin otoritas penggunaan sistem hanya oleh Apoteker/TTK Penanggung Jawab

- harus bisa menjamin ketertelusuran produk ( $\min 5$ th)

- harus dapat ditunjukan dan dipertanggungjawabkan kebenarannya pada saat pemeriksaan

- harus tersedia sistem backup data

Sistem

Elektronik

- harus mudah dalam evaluasi \& penarikan data pada saat dibutuhkan

- Ada mekanisme pemberitahuan secara elektronik dari pihak pemasok bahwa pesanan tersebut telah diterima

- Pengadaan NPP harus dilengkapi SP manual asli, 7 (tujuh) hari setelah konfirmasi dari pihak pemasok

\section{Manual}

- asli dan dibuat sekurang-kurangnya rangkap 2 (NPP 3) serta tidak dibenarkan dalam bentuk faksimili dan fotokopi

- ditandatangani oleh Apt/TTK PJ, nama jelas, dan nomor SIPA/SIPTTK

Fasilitas pelayanan kefarmasian sudah saatnya berbenah termasuk tenaga kefarmasian (apoteker dan tenaga teknis kefarmasian), untuk mulai mengimplementasikan system elektronik secara bertahap, ditengah ekosistem bisnis yang sedang mengalami turbulensi, sebagai akibat pengaruh disruption kefarmasian.

\section{CATATAN PENGOBATAN PASIEN (PATIENT MEDICATION RECORD)}

Nama

$(L / P)$

Alamat

No. Telp

\begin{tabular}{|l|l|l|l|l|l|l|}
\hline Tgl R/ & $\begin{array}{c}\text { Dokter } \\
\text { (Nama, Alamat, No. Telp) }\end{array}$ & Obat yang Diberikan & $\begin{array}{c}\text { Dosis / } \\
\text { Hari }\end{array}$ & Frekuensi & $\begin{array}{c}\text { Tgl. Obat } \\
\text { Diberikan }\end{array}$ & $\begin{array}{c}\text { Tgl. Obat } \\
\text { Habis }\end{array}$ \\
\hline \hline & & & & & & \\
\hline & & & & & & \\
\hline
\end{tabular}

Usia :

Alergi :

Penyakit Lain (Kronis) :
No. Telp : 
FORMAT INSTRUMEN MONITORING

NAMA FASKES :

ALAMAT :

\begin{tabular}{|c|c|c|c|c|c|c|}
\hline \multirow[b]{2}{*}{ NO } & \multirow[b]{2}{*}{ KOMPONEN PENILAIAN } & \multirow{2}{*}{$\begin{array}{c}\text { Вовот } \\
(\%)\end{array}$} & \multicolumn{3}{|c|}{ HASIL PENILAIAN } & \multirow[b]{2}{*}{ TELUSUR } \\
\hline & & & $\begin{array}{l}\text { ADADAN } \\
\text { SESUAI }\end{array}$ & $\begin{array}{c}\text { ADA TIDAK } \\
\text { SESUAI }\end{array}$ & $\begin{array}{l}\text { TIDAK } \\
\text { ADA }\end{array}$ & \\
\hline \multirow[t]{9}{*}{ A } & ADMINISTRASI & 30 & & & & \\
\hline & $\begin{array}{l}\text { 1. Sertifikat Kompetensi Profesi Apoteker } \\
\text { (SKPA)* }\end{array}$ & 4 & & & & Masa berlaku \\
\hline & 2. Surat Tanda Registrasi Apoteker (STRA)* & 4 & & & & Masa berlaku \\
\hline & 3. Surat Izin Praktik Apoteker (SIPA)* & 4 & & & & Masa berlaku \\
\hline & 4. Surat Izin Apotek (SIA)* & 4 & & & & Masa berlaku \\
\hline & $\begin{array}{l}\text { 5. Surat Tanda Registrasi Tenaga Teknis } \\
\text { Kefarmasian (STRTTK) }\end{array}$ & 4 & & & & Masa berlaku \\
\hline & $\begin{array}{l}\text { 6. Surat Izin Praktik Tenaga Teknis } \\
\text { Kefarmasian (SIPTTK) }\end{array}$ & 4 & & & & Masa berlaku \\
\hline & $\begin{array}{l}\text { 7. SOP Pengelolaan Sediaan Farmasi, Alkes } \\
\text { dan BMHP* }\end{array}$ & 3 & & & & $\begin{array}{l}\text { Lengkap/Tidak } \\
\text { Lengkap }\end{array}$ \\
\hline & 8.SOP Pelayanan Farmasi Klinis * & 3 & & & & Lengkap/Tidak \\
\hline \multirow[t]{7}{*}{ B } & SUMBER DAYA MANUSIA KESEHATAN & 20 & & & & \\
\hline & 1. Jumlah Apoteker & 3 & & & & Minimal 2 orang \\
\hline & 2. Jumlah TTK & 3 & & & & Minimal 2 orang \\
\hline & $\begin{array}{l}\text { 3. Pemberi Pelayanan Apoteker Pemegang } \\
\text { SIA }\end{array}$ & 5 & & & & Document \\
\hline & 4. Pemberi Pelayanan Apoteker Praktik & 4 & & & & Document \\
\hline & 5. Pemberi Pelayanan TTK & 3 & & & & Document \\
\hline & 6. Pemberi Pelayanan Petugas Lain & 2 & & & & \\
\hline \multirow[t]{8}{*}{ C } & $\begin{array}{l}\text { PENGELOLAAN SEDIAAN FARMASI, ALKES \& } \\
\text { BMHP }\end{array}$ & 14 & & & & \\
\hline & 1. Perencanaan & 2 & & & & Ada dokumen RKO \\
\hline & 2. Pengadaan & 2 & & & & $\begin{array}{l}\text { Dari Distributor/Sub } \\
\text { Distributor Resmi }\end{array}$ \\
\hline & 3. Penerimaan & 2 & & & & Ada dokumen \\
\hline & 4. Penyimpanan & 2 & & & & $\begin{array}{l}\text { FIFO, FEFO atau } \\
\text { Kombinasi }\end{array}$ \\
\hline & 5. Pemusnahan & 2 & & & & Ada Dokumen \\
\hline & 6. Pengendalian & 2 & & & & Ada Kartu Stok/SIM \\
\hline & 7. Pencatatan dan Pelaporan & 2 & & & & Ada Dokumen \\
\hline \multirow[t]{6}{*}{ D } & KELENGKAPAN PRAKTIK APOTEKER & 10 & & & & \\
\hline & 1. Papan Nama Praktik Apoteker & 2 & & & & Sesuai PO \\
\hline & 2. Jam Praktik & 2 & & & & Sesuai dengan SIPA \\
\hline & 3. Hari Praktik & 2 & & & & Sesuai PO \\
\hline & 4. Jas Praktik & 2 & & & & Sesuai PO \\
\hline & 5. Kehadiran Apoteker* & 2 & & & & $\begin{array}{l}\text { Minimal } 3 \text { jam/hari } \\
\text { (Absensi) }\end{array}$ \\
\hline
\end{tabular}


SOEPRA Jurnal Hukum Kesehatan

ISSN:2548-818X (media online) Vol. 5 (2) Desember 2019

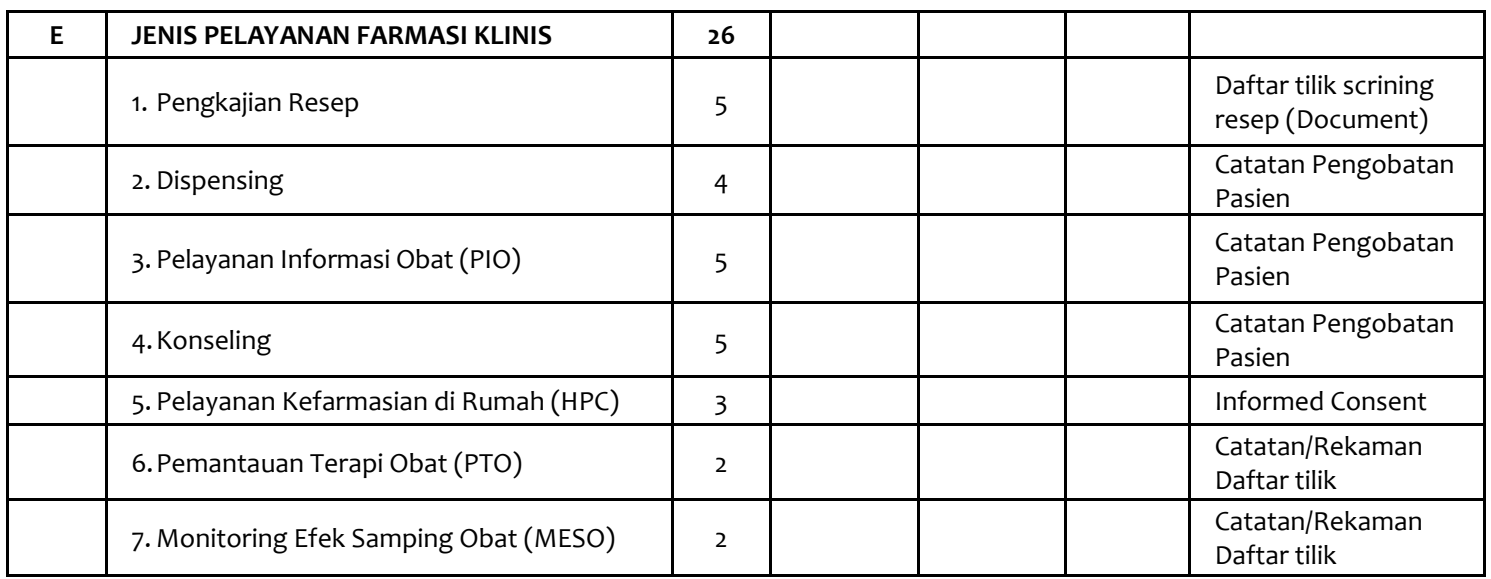

Keterangan :

- $\left.\quad{ }^{*}\right)$ Wajib ada, Jika tidak ada nilai $=0$

- Ada dan sesuai nilai $=2$

- Ada tidak sesuai nilai = 1

- Apabila score nilai 53-66 = A

- Apabila score nilai 40-52 = B

- Apabila score nilai $<40=C$

\section{KESIMPULAN}

Dalam rangka pencegahan medication errors maka eMAR dan CPOE dapat dikembangkan menjadi suatu sistem informasi kesehatan berupa teknologi yang akan lebih efektif, efisien dan mudah digunakan dan didapatkan serta mudah dirawat/diperbaiki.

Perlu dukungan dari semua pihak khususnya regulator, top manajer, tenaga kesehatan dalam penggunaan eMAR dan CPOE di rumah sakit, klinik, puskesmas, dan apotek. Dukungan yang sangat penting ada pada rancangan Peraturan Menteri Kesehatan, seperti PSEF (Penyedia Sarana Elektronik Farmasi) dengan catatan ditambahkan klausul eMAR dan CPOE.

Rumah sakit, klinik, puskesmas, dan apotek perlu mempertimbangkan pelaksanaan eMAR dan CPOE, dengan melakukan perencanaan yang tepat dengan mengalokasikan sumber daya yang cukup besar untuk membangun sistem eMAR dan CPOE, mendidik, melatih tenaga kesehatan dan melakukan evaluasi pelaksanaan eMAR dan CPOE.

\section{SARAN}

Kemenkes sudah saatnya merevisi draft Permenkes tentang Penyedia Sarana Elektronik Farmasi (PSEF), utamanya memasukkan klausul eMAR dan CPOE.

Sebaiknya seluruh tenaga kesehatan yang ada di institusi kesehatan termasuk tenaga kefarmasian hendaknya menyadari betapa pentingnya pengembangan teknologi informasi.

Kebutuhan tenaga perekam medis sudah dapat menunjukkan kontribusi yang signifikan pada era pelayanan kesehatan semesta.

Karena teknologi bermanfaat untuk memberikan pengetahuan terkini dalam meningkatkan mutu pelayanan kesehatan pada era pelayanan kesehatan semesta dan dapat sebagai pembelajaran bagi institusi pelayanan kesehatan dalam mengatasi permasalahan di pelayanan kesehatan. 


\section{DAFTAR PUSTAKA}

Undang-undang Nomor 8 Tahun 1999 tentang Perlindungan Konsumen

Undang-undang Nomor 11 Tahun 2008 tentang Informasi dan Transaksi Elektronik

Undang-unadang Nomor 36 Tahun 2009 tentang Kesehatan

Peraturan Pemerintah Nomor 72 Tahun 1998 tentang Pengamanan Sediaan Farmasi dan Alat Kesehatan

Peraturan Pemerintah Nomor 51 Tahun 2009 tentang Pekerjaan Kefarmasian

Peraturan Pemerintah Nomor 82 Tahun 2012 tentang Penyelenggaran Sistem dan Transaksi Elektronik

Peraturan Menteri Kesehatan Nomor 72 Tahun 2016 tentang Standar Pelayanan Kefarmasian di Rumah Sakit

Peraturan Menteri Kesehatan Nomor 73 Tahun 2016 tentang Standar Pelayanan Kefarmasian di Apotek

Peraturan Menteri Kesehatan Nomor 74 Tahun 2016 tentang Standar Pelayanan Kefarmasian di Puskesmas

Peraturan Menteri Kesehatan Nomor 9 Tahun 2017 tentang Apotek

Peraturan Menteri Kesehatan Nomor 26 Tahun 2018 tentang Perizinan Berusaha Terintegrasi Secara Elektronik

Alanazi, Alomar, Aldosari, Shahrani, Aldosari. The Effect of Electronic Medication Administration Records on the Culture of Patient Safety: A Literature Review.

Mahesa Pranadipta, Keuntungan dan Kerugian Pelayanan eHealth di era Digitalisasi, PIT Hisfarma PP IAI, Manado 2018

NAHIT Report to the ONC on Defining Key Health Information Technology Terms. Department of Health and Human Services, 2008

Key Capabilities of an Electronic Health Record System, Institute of Medicine,2003 